\title{
Studiemateriaal Discipline interne geneeskunde
}

\author{
H.M.S. van Santen-Hoeufft, J.R.E. Haalboom, S.A. Danner
}

\section{Besproken studiemateriaal}

1. Harrison's Principles of Internal Medicine, A.S. Fauci, E. Braunwald et al.

2. Textbook of Internal Medicine, W.N. Kelley

3. Cecil Textbook of Medicine, L. Goldman, J. C. Bennett

4. Clinical Medicine, P.J. Kumar, M.L. Clark

5. Textbook of Medicine, R.L. Souhami, J. Moxham

6. Current Medical Diagnosis, L.M. Tierney, S.J. McPhee, M.A. Papdakis

7. Medicine, J. Axford

8. Interne Geneeskunde, J. van der Meer, C.D.A. Stehouwer, G.J.H. den Ottolander

\section{Inleiding}

De interne geneeskunde biedt studieboeken in de vorm van respectabele naslagwerken, beroemd geworden onder een eigen- of plaatsnaam, zoals 'de' Harrison, Kelley, Cecil, Siegentahler en Oxford. Deze bevatten meer dan 2000 bladzijden tekst en minstens 150 pagina's index en zijn kwalitatief zeer goed. De Harrison en de Oxford bieden tevens een versie op cd-rom. Om voor een dubbeltje per pagina op de eerste rij te kunnen zitten, selecteerden we voor de beoordeling de eerste drie naslagwerken. Vroeger was het pas bij het begin van de co-assistentschappen, ofwel in het vijfde jaar, gangbaar om over een groot naslagwerk te beschikken. Tegenwoordig hebben alle curricula de kennismaking met 'echte' interne-geneeskundige problemen naar voren geschoven. De behoefte aan een studieboek dat wat minder diepgaand en prettiger leesbaar is, liefst voorzien van veel schema's en illustraties, is met name voor de jongerejaars studenten zeer invoelbaar. Hiervan zijn er minstens tien Engelstalige op de markt. We kozen voor de bespreking de meest gebruikte, namelijk Kumar, Souhami en Axford. De vertrouwde 'Den Ottolander', inmiddels al jaren 'Van der Meer', is vanwege zijn Nederlandstaligheid onder studenten populair gebleven en derhalve meegewogen. Tot slot is ook Tierney's Current medical diagnosis in de beoordeling meegenomen, omdat dit boek tot nog toe het meest verregaand is in een bijpassend multimedia aanbod.

De werkwijze was als volgt: alle boeken werden getest op de beoordelingscriteria, zoals vermeld in de tabel. Voor het nagaan van de gebruiksvriendelijkheid, diepgang, relevantie en dergelijke werden de boeken voorgelegd aan een groep eind-derdejaars en vijfdejaars studenten. Op de checklist stonden de willekeurig gekozen problemen koorts, moeheid en spierpijn, de pathofysiologie van hypertensie, alle aspecten van sarcoïdose, het voorkomen van psychosomatosen en tot slot de vraag wat geriatrie tot een aparte discipline maakt.

$\mathrm{Na}$ de besprekingen volgt een overzicht van de aanbevolen boeken in zeven medische faculteiten in het jaar 1999/2000 (van de Vrije Universiteit werd geen opgave ontvangen).

\section{Beknopte bespreking}

\section{A.S. FAUCI, E. BRAUNWALD, K.J. ISSELBACHER, J.D. WILSON, J.B. MARTIN, D.L. KASPER, S.L. HAUSER EN D.L. LONGO. HARRISON'S PRINCIPLES OF INTERNAL MEDICINE. NEW YORK: MCGRAW- HILL; 1999 (STUDENTENEDITIE).}

Een zeer goed standaardwerk. Het bevat een aantal probleemgerichte en omgevingsgerichte 
hoofdstukken naast de gebruikelijke aanpak uitgaand van een ziekte-entiteit. Neurologische aandoeningen komen uitvoerig aan de orde, meer psychologisch getinte klachten of aandoeningen minder. Relatief weinig, maar bruikbare tabellen. Klein, maar kwalitatief fraai platenatlasgedeelte. De studenten hadden weinig moeite de zoekopdrachten uit te voeren in de Harrison. De goedkopere studentenversie van 1999 is een reprint van de professionele versie van 1997, hetgeen verklaart waarom de referenties aan de oudere kant zijn. Als enig groot naslagwerk interne geneeskunde biedt de Harrison een on-line verbinding en een cd-rom. Deze laatste leverde, bij alles wat de studenten zochten, zo veel hits op dat hij niet echt gebruikersvriendelijk overkwam.

\section{W.N. KELLEY, TEXTBOOK OF INTERNAL MEDI- CINE. Philadelphia: LipPincott-RaVEN; 1997 (2B: VIERDE DRUK).}

Dit standaardwerk heeft een plezierige vormgeving met overzichtelijke sub-hoofdjes en tabellen. De weinige foto-illustraties zijn van matige kwaliteit. De basale pathofysiologie komt goed aan de orde. De index schiet hier en daar tekort als je een probleem als ingang neemt, merkten de studenten op. Daarentegen is het telkens terugkerende 'approach to the patient' zeer bruikbaar, zodra de diagnose bekend is. Psychosomatosen komen slechts summier aan bod in de Kelley, maar de overige zoekopdrachten leverden geen problemen op. In september 2000 verscheen de vierde druk, die aanmerkelijk meer pagina's heeft dan de hierboven beoordeelde editie. Er is meer aandacht voor 'evidence-based medicine'. De 'clinical decision guides' zijn handig. Dit boek onderscheidt zich van de andere door de aanwezigheid van een 'rapid access guide'. Hierin worden de 149 ziektes en syndromen waarvoor het vaakst verwezen wordt naar een internist, kort en bondig besproken. Waardevol in situaties met tijdsdruk! Bovendien een concurrerende prijs.

\section{L. Goldman, J.C. Bennett. Cecil TeXtbook of Medicine. Philadelphia: W.B. SAUNDERs; 2000.}

Een gedegen naslagwerk met extra veel aandacht voor de overlap tussen de interne geneeskunde en andere disciplines. Zo is er niet alleen een apart hoofdstuk gewijd aan de neurologie (dat hebben alle Amerikaanse naslagwerken), maar ook aan de KNO-heelkunde en dermatologie. Het boek bevat de meest uitgebreide kleurenatlas, waar ook het bewegingsapparaat in beeld komt. De tabellen en grafieken zijn van goede kwaliteit, de weergave van scans en foto's iets minder. Door het kleine lettertype leest het minder makkelijk. Uitvoerige en bruikbare index, waarmee de studenten alle zoekopdrachten zonder noemenswaardig probleem konden vinden. De pathofysiologische besprekingen zijn wisselend van diepgang. Weinig, maar actuele literatuurverwijzingen.

\section{P.J. Kumar, M.L. Clark. Clinical Medicine. PhiladelPhia: W.B. SAUNDERS; 1998.}

Kumar is een prettig leesbaar boek met een prachtige vormgeving. De gedetailleerde tekst wordt onderbouwd met kwalitatief goede schema's, tabellen, afbeeldingen van radiodiagnostiek en histologische preparaten, en dergelijke. Per topic handige overzichtsblokjes. Opvallend was de moeite die de studenten hadden om de pre-gedefinieerde zoekopdrachten uit te voeren. Deels kan dit op het conto geschreven worden van de index: die is matig, met uitzondering van de wel uitvoerig behandelde psychosomatosen.

\section{R.L. Souhami, J. Moхham. TeXtbook of MEDICINE. EDINBURGH, CHURCHILL LIVING- STONE; 1997 (REPRINTED 1999).}

Souhami levert een overzichtelijk, prettig leesbaar boek met goed uitgewerkte, verhelderende illustraties. Het is overwegend orgaangericht opgebouwd en volgt telkens het patroon van structuur/functie, symptomen/bevindingen en onderzoekstechnieken naar ziektes. Daarnaast zijn er aparte inleidende hoofdstukken over epidemiologie, doelmatig diagnostisch handelen en farmacotherapie. De referenties in de 'further reading'-adviezen zijn aan de oude kant, hetgeen wordt gecompenseerd door leuke, bruikbare blokjes 'recent advances'. De studenten konden met dit boek goed overweg ten aanzien van de pre-gedefinieerde opdrachten, behalve bij de probleemaanpak: geen 'fatigue', 'fever' of 'myalgia' in de index! Overigens zeer geschikt voor oriëntatie in de interne geneeskunde. 


\section{L.M. TIERNEY JR, S.J. MCPHEE, M.A. PAPDAKIS. CURRENT MEDical Diagnosis. NEW York: MCGRAW-HILL; 2000.}

Dit boek komt saai over door zijn eenvoudige vormgeving: heel weinig tabellen, nauwelijks illustraties. De verwijzing naar de artikelen (inclusief wat voor soort studie het betreft) is up to date. Current medical diagnosis is het enige boek met verwijzing naar webpagina's. Het bevat een gratis cd-rommonster als smaakmaker voor de binnenkort te verschijnen multimediale cd-rom inclusief gids voor diagnostische tests, gids voor farmacotherapie, illustraties, hart/longgeluiden et cetera (ongeveer $f 430$,-). Op zijn minst klinkt dit veelbelovend!

\section{J. AXFORD (RED.). MEDICINE. OXFORD: BLACK- WELL SCIENCE; 1996.}

Ieder die de Axford openslaat, krijgt het idee dat de interne geneeskunde eenvoudig te vangen is in kleurrijke tabellen, flowcharts, illustraties, foto's en dergelijke. De kwaliteit is prima, maar door de drukke lay-out lijkt de tekst welhaast ondergesneeuwd. De doorverwijzingen naar andere pagina's zijn handig, evenals de 'at a glance' samenvattingen. Er zijn geen literatuurverwijzingen en diepgang ontbreekt, maar het maakt interne geneeskunde wel 'leuk'. Geschikt voor eerste- en tweedejaars studenten, vooral om enthousiasme voor het vak te wekken.

\section{J. VAN DER MEER, C.D.A. STEHOUWER, G.J.H. DEN OTTOLANDER. INTERNE GENEESKUNDE. HOUTEN: BOHN STAFLEU VAN LOGHUM; 1996.}

Dit is en blijft een Nederlandstalig, gedegen, sober leerboek zonder de opsmuk van kleurillustraties en dergelijke. Veel compacte informatie. Vaak literatuurverwijzingen naar andere boeken in plaats van recente overzichtsartikelen. De zoekopdracht naar de tevoren vastgestelde willekeurige leerdoelen verliep teleurstellend: de problemen moeheid en myalgie waren niet via de index of anderszins te vinden, de pathofysiologie van sarcoïdose bleek oppervlakkig en psychosomatosen komen evenmin uit de verf. Daarentegen was wel kwalitatief goede informatie over geriatrie en hypertensie te vinden. Ondanks alles blijft voor velen toch de moerstaal het makkelijkst.

Tabel 1. Interne geneeskundeboeken op de advies- of kernlijst bij zeven faculteiten 1999/2000

\begin{tabular}{llcccccc}
\hline & EUR & KUN & LUMC & RUG & UM & UMC-U & AMC \\
\hline 1. Harrison & & + & + & & + & + & + \\
2. Kelley & & & & & + & & \\
3. Cecil & & & & & & & \\
4. Kumar & & + & & & & + & \\
5. Souhami & + & & & + & + & & + \\
6. Tierney & & & & & & & \\
7. Axford & & & & & & \\
8. Vander Meer & & & & & & & \\
\hline
\end{tabular}




\begin{tabular}{|c|c|c|c|c|c|c|c|c|c|}
\hline Beoordeelde kenmerken & 1 & 2 & $2 b$ & 3 & 4 & 5 & 6 & 7 & 8 \\
\hline Relevantie voor artsopleiding & 5 & 5 & 5 & 5 & 5 & 5 & $4^{*}$ & $3^{* *}$ & 4 \\
\hline $\begin{array}{l}\text { Relevantie v. medische biologie } \\
\text { en gezondheidswetenschappen }\end{array}$ & 3 & 3 & 3 & 3 & 2 & 2 & 2 & 1 & 2 \\
\hline Inhoudelijke kwaliteit & 5 & 4 & 5 & 5 & 4 & 4 & 4 & 3 & 3 \\
\hline Vormgeving & 4 & 4 & 4 & 4 & 5 & 4 & 3 & 5 & 3 \\
\hline $\begin{array}{l}\text { Didactische kwaliteit } \\
\text { ('studeerbaarheid') }\end{array}$ & 5 & 4 & 5 & 5 & 4 & 5 & $3^{*}$ & 5 & 3 \\
\hline $\begin{array}{l}\text { Geschikt als verplichte } \\
\text { zelfstudiestof }\end{array}$ & 5 & 4 & 5 & 5 & 5 & 5 & 3 & $3^{* *}$ & 4 \\
\hline $\begin{array}{l}\text { Kwaliteit verwijssystematiek en } \\
\text { dekking van materie }\end{array}$ & 5 & 4 & 5 & 5 & 4 & 5 & 4 & 3 & 3 \\
\hline $\begin{array}{l}\text { Aan te bevelen om zelf aan te } \\
\text { schaffen }\end{array}$ & 5 & 4 & 5 & 5 & 5 & 5 & $3^{*}$ & $3^{* *}$ & 3 \\
\hline Geschiktheid voor gehele studie & 5 & 4 & 5 & 5 & 4 & 4 & $3^{*}$ & 3 & 4 \\
\hline Kwaliteit voorbeelden/casus & - & - & - & - & - & - & - & - & - \\
\hline $\begin{array}{l}\text { Kwaliteit studieopdrachten of } \\
\text { vragen }\end{array}$ & - & - & - & - & - & - & - & - & - \\
\hline $\begin{array}{l}\text { Kwaliteit antwoorden bij } \\
\text { studieopgaven of vragen }\end{array}$ & - & - & - & - & - & - & - & - & - \\
\hline \multicolumn{10}{|l|}{ Beschrijvende kenmerken } \\
\hline Taal & $\mathrm{E}$ & $E$ & $E$ & $E$ & $E$ & E & $E$ & $E$ & $\mathrm{~N}$ \\
\hline Omvang in pagina's & 2569 & 2581 & 3254 & 2308 & 1326 & 1218 & 1735 & 1200 & 1092 \\
\hline $\begin{array}{l}\text { Omvang (breedte maal hoogte, } \\
\text { afgerond in } \mathrm{cm} \text { ) }\end{array}$ & $21 \times 29$ & $21 \times 29$ & $21 \times 28$ & $21 \times 28$ & $19 \times 27$ & $21 \times 26$ & $18 \times 24$ & $22 \times 27$ & $20 \times 26$ \\
\hline Aantal delen & 2 & 2 & 1 & 1 & 1 & 1 & 1 & 1 & 1 \\
\hline Druk & 14 & 3 & 4 & 21 & 4 & 3 & 39 & 1 & 11 \\
\hline Jaar van uitgave & 1999 & 1997 & 2000 & 2000 & 1998 & 1997 & 2000 & 1996 & 1996 \\
\hline Jaar van eerste druk & 1958 & 1989 & 1989 & 1927 & 1987 & 1990 & 1987 & 1996 & 1969 \\
\hline Prijs (in guldens) & 277 & 250 & 201 & 250 & 135 & 155 & 135 & 105 & 129 \\
\hline
\end{tabular}

Beoordeling: 1 = zeer slecht/zeer gering/zeer ongeschikt; 2 = slecht/gering/ongeschikt; 3 = matig; 4 = goed/groot/geschikt; 5 = zeer goed/zeer groot/zeer geschikt; - = niet van toepassing

* aanvullende multimediale cd-rom nog niet beschikbaar, beoordeling betreft uitsluitend het boek

** zeer geschikt voor de eerste studiejaren 